\title{
Grußwort der BRAK-Präsidenten
}

Mit der 1878 vom Reichstag verabschiedeten Rechtsanwaltsordnung wurde der Grundstein für eine freie, vom Staat unabhängige Selbstverwaltung der Anwaltschaft in Deutschland gelegt. Regionale Rechtsanwaltskammern, gebildet aus den im Bezirk eines Oberlandesgerichts zugelassenen Rechtsanwälten, erhielten die Aufgabe übertragen, selbständig und nur einer rechtlichen staatlichen Kontrolle unterworfen die Aufsicht über ihre Mitglieder auszuüben, bei Streitigkeiten untereinander oder mit Mandanten zu vermitteln und auf Aufforderung der Landesjustizverwaltung bzw. von Gerichten Rechtsgutachten zu erstellen. Bis heute gehört sie zum Kanon der den Rechtsanwaltskammern gesetzlich zugewiesenen Pflichten, allerdings um eine Vielzahl von zusätzlichen Aufgaben erweitert. Und sie hat sich bewährt: Die anwaltliche Selbstverwaltung steht nicht in Frage, sondern ist fester, ja notwendiger Bestandteil rechtsstaatlicher Ordnung. Nicht zuletzt beweist dies die schnelle Gründung regionaler Rechtsanwaltskammern in den neuen Ländern nach der Wiedervereinigung ein Beleg für den dringenden Wunsch auch der in der Deutschen Demokratischen Republik tätigen Rechtsanwälte nach einer selbstverwalteten Anwaltschaft.

Zunehmend seit der Jahrtausendwende hat die anwaltliche Fachliteratur in einzelnen Aufsätzen, in Monografien und in umfangreichen Büchern die Geschichte der deutschen Anwaltschaft aufgearbeitet. Wie sich das Berufsbild des Rechtsanwalts in mehr als hundert Jahren gewandelt hat, ohne seine Funktion als unabhängiger, verschwiegener und loyaler Berater und Vertreter in allen Rechtsangelegenheiten zu verlieren, wird an unterschiedlichsten Stellen eindrucksvoll beschrieben. Und welche Entwicklung die einzelnen Rechtsanwaltskammern dabei genommen haben, ist in einer Vielzahl von mehr oder minder umfangreichen Veröffentlichungen, regelmäßig von ihnen selbst aus Anlass von Jubiläen herausgegeben, dokumentiert.

Was bisher fehlte, ist eine Geschichte der Bundesrechtsanwaltskammer, der Dachorganisation der regionalen Kammern in Deutschland, gegründet erst 1959 mit der Verabschiedung der Bundesrechtsanwaltsordnung durch den Deutschen Bundestag.

Wir, die ehemaligen Präsidenten der Bundesrechtsanwaltskammer und ihr amtierender Präsident, sind dankbar, dass es gelungen ist, diese Lücke zu schließen. Wir wünschen dem Werk eine nachhaltige Verbreitung!

Bremen, Berlin, Hamburg, Ravensburg und Münster,

Dr. Eberhard Haas im Sommer 2019

Dr. Bernhard Dombek

Axel C. Filges

Ekkehart Schäfer

Dr. Ulrich Wessels 
